\title{
Correspondence
}

\author{
Letters to the Editor should not exceed 500 words.
}

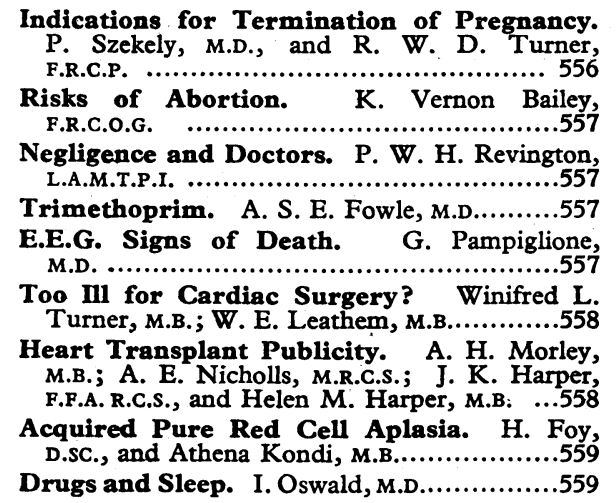

Avantages of Fenfluramine.

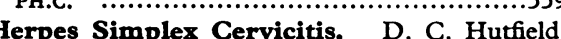
M.D. ........................................560 Long-term Anticoagulant Therapy. F. NourEldin, PH.D., M.C.PATH. .....................560 Sterilization-Male or Female? R. S. Saxton, D.T.M.\&H..................................560 The "Public Drunk." P. M. J. O'Brien, M.R.C.P. ....................................560 Mothers and Children in Hospital. S. $R$. Meadow, M R.P. Haemophilus Septicaemia. J. L. Greaves, M.D. ..........................................560 Monoamine Oxidase Inhibitors and Anaesthesia. J. W. Warrick, F.F.A. R.C.S...........561 Idiopathic Facial Palsy. E. D. R. Campbell, M.R.C.P. ......................................561
Zinc Sulphate and Bedsores. Cyril Cohen, M.R.C.P.ED. ..................................561 Paracervical Block with Bupivacaine. F. C. R. Picton, F.R.C.O.G. ........................... 561 Cirrhosis of the Liver. B. L. Agarwal, M.D.
Folate Requirement in Pregnancy. M. L. N. Willoughby, M.D. ..........................562 Low-dosage Oral Progestogen. W. P. Black,

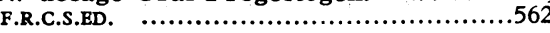
Brand Names. L. Wislicki, M.D. .............562 Gender and Sex. A. McKie Reid, F.R.c.s.; P. D. Trevor-Roper, F.R.C.S. ...............562 Medical Assistants' Seniority. W. I. Martin, M.B. ......................................563 Role of the B.M.A. W. Ferguson, D.P.H.; A. V. Russell, M.B. .................................563 Surgical Tutors. D. W. Bracey, F.R.C.S.ED....563

\section{Indications for Termination of Pregnancy}

SIR,-We have studied with interest and some concern the report by the B.M.A. Committee on Indications for Termination of Pregnancy (20 January, p. 171), and find it shows an apparent lack of appreciation of the many changes made in the last 20 years in assessment and treatment of cardiovascular conditions.

The report does not differentiate between the varieties of cardiac failure in pregnancy, and presumably pulmonary congestion, pul monary oedema, and the clinical picture which for convenience may be termed right heart failure have been taken together. It is also apparently accepted that symptoms necessarily reflect the severity of the underlying heart disease. It states that " severity has been classified for convenience into four main grades, beginning with that in which symptoms occur only on very vigorous activity, to the other extreme of total incapacity. . . Maternal mortality in cardiac failure ranges from approximately $2 \%$ in the milder cases to $18 \%$ in the severe. Where atrial fibrillation coexists with failure the mortality may reach $32 \%$ "-that is, as judged apparently by this functional classification which corresponds to that recommended by the New York Heart Association (N.Y.H.A.) some years ago. It goes on to say that " in nonpregnant controls corresponding figures would be $2 \%, 6.7 \%$, and $8 \%$ respectively."

These figures certainly do not reflect the present situation in this country. For example, in a large series of patients observed in Newcastle since 1942 atrial fibrillation was present in 56 patients in 66 pregnancies. Only nine developed right heart failure and three pulmonary oedema, and only one of these patients died. There were two more deaths in the total atrial fibrillation group, not associated with heart failure: both deaths were sudden and due to pulmonary embolism and obstruction of the tricuspid orifice by an aneurysm of the atrial septum, respectively. ${ }^{2}$ Also it is not atrial fibrillation which is so important as the presence or absence of associated adverse factors. The facts are that maternal mortality from heart disease in pregnancy has fallen to very low levels in recent years, and the usual cause for patients reaching functional grade 3 or 4 is severe mitral stenosis, which can be treated surgically.

The functional classification to which the report refers is an unreliable and potentially dangerous guide to the severity of the underlying heart disease. The only sure basis for correct assessment is to rely on objective findings. Experience has shown that potentially the most dangerous situation is moderate to severe mitral stenosis in a patient who is still practically symptom-free, because it is this type of patient who can suddenly develop fatal pulmonary oedema in pregnancy if the mitral stenosis remains surgically unrelieved.

It also goes on to say that " if by the end of this period [the middle trimester] the patient's condition has hitherto been satisfactory there could well be a reasonable chance of uneventful procedure to term." I is an error to assume that the cardiac output begins to fall at about the 32 nd week of pregnancy and that the remaining period is there fore relatively safe, so that termination will prove unnecessary. It has been shown by various workers that the cardiac output rises to a maximum early in pregnancy and thereafter remains fairly constant, there being no fall towards full term. ${ }^{23}$ These findings are reflected in clinical experience. The facts are that more often than not women who develop pulmonary oedema do so in the last three months. In the Newcastle series 25 attacks developed in 20 pregnancies in 18 patients. Twelve of these 25 occurred after the 30th week and five in the puerperium. Experience in Edinburgh has been similar. Heart disease frequently deteriorates throughout pregnancy, and a maternal death may occur at any stage. Our experience is similar to that summarized in the Ministry of Health Confidential Reports on Maternity Mortality, there being an equal distribution from the 6 th to the 39 th week.

As regards congenital heart disease the report states that "some conditions are amenable to surgical intervention without interfering with the pregnancy-for example, persistent ductus arteriosus, interatrial septal defect, and Fallot's tetralogy." However, these conditions are very different. Although rarely necessary, a patent ductus can always be divided or ligated at any stage of pregnancy. Closure of an atrial septal defect requires either hypothermia or open heart surgery, and again is rarely necessary during pregnancy. Repair of Fallot's tetralogy makes open heart surgery imperative with its prohibitive risk to the foetus. It is stated that "termination may have to be considered in severe cases of ventricular septal defect" without indicating whether a large defect is meant or one with associated pulmonary hypertension and reversed shunt. If there is a large defect with cardiac failure, which is most uncommon in pregnancy, termination may be advisable, and if there is a reversed shunt it is imperative. However, termination should be carried out only after adequate medical control of the heart failure.

Comments made in the report on certain types of heart disease such as thyrotoxicosis and ischaemic heart disease do not indicate the rarity of these conditions during pregnancy. Finally, we have not seen a patient in whom termination had to be advised on account of arrhythmias alone nor of heart block.

A clear statement of the present position as regards heart disease in pregnancy and its management would be helpful, emphasizing the rarity with which termination need be advised. We would plead for an early revision of the cardiovascular section of the present report.-We are, etc.,

$$
\begin{aligned}
& \text { P. Szekely. } \\
& \text { Cardiovascular Department, } \\
& \begin{array}{l}
\text { Newcastle General Hospital } \\
\text { Newcastle upon Tyne. }
\end{array} \\
& \text { R. W. D. TURNER. }
\end{aligned}
$$

\section{Cardiac Department,}

REFERENCES

1 Szekely, P., and Snaith, L., Brit. med. F., 1961 ,

1, 1407. Eytten, F. E., and Leitch, I., The Physiology of

Human Pregnancy, 1964 . Oxford.
Kerr, M. G, Brit. med. Bull., 1968, 24, 19. 